\title{
Pengembangan Mobile Learning Barusikung Berbasis Android pada Materi Bangun Ruang Sisi Lengkung
}

\author{
Yesica Puspita Rachma1 ${ }^{*}$, Danang Setyadi2, dan Helti Lygia Mampouw ${ }^{3}$ \\ 1,2,3Pendidikan Matematika, FKIP, Universitas Kristen Satya Wacana \\ Jalan Diponegoro No. 56-60, Salatiga, Jawa Tengah, Indonesia \\ 1*202016055@student.uksw.edu,2danang.setyadi@uksw.edu,3helti.mampou@uksw.edu
}

Artikel diterima: 05-02-2020, direvisi: 26-09-2020, diterbitkan: 30-09-2020

\begin{abstract}
Abstrak
Matematika merupakan salah satu pelajaran yang penting untuk dikuasai siswa di sekolah khususnya pada materi pemahaman bentuk dan ruang, meskipun demikian masih banyak siswa yang mengalami kesulitan dalam mempelajari materi tersebut. Hal inilah yang mendorong peneliti untuk mengembangkan suatu aplikasi Mobile learning pada materi Bangun Ruang Sisi Lengkung. Penelitian ini merupakan penelitian pengembangan dengan menggunakan model ADDIE. Langkah-langkahnya terdiri dari: Analysis, Design, Development, Implementation, dan Evaluations. Hasil penelitian menunjukkan bahwa media yang dikembangkan valid dan praktis. Hasil uji coba terhadap 10 siswa menunjukkan bahwa media masuk dalam kategori baik. Selain itu Mobile learning mampu meningkatkan hasil belajar siswa, hal ini dapat dilihat dari hasil pretest dan posttest yang menunjukkan nilai signifikan. Mobile learning dapat membantu siswa memahami bentuk dan ruang pada materi Bangun Ruang Sisi Lengkung.

Kata Kunci: Android, Bangun Ruang Sisi Lengkung, Media Pembelajaran, Mobil Learning.
\end{abstract}

\section{The Expansion of Mobile Learning Barusikung Base Android on Solid Geometry}

\begin{abstract}
Mathematics is one of the important subjects that students having to do in school especially to know shapes and geometry, although it is important to learn, many students still have difficulties in studying the material. It promotes the researcher to encourage an application of Mobile learning to solid geometry. This research is research and development using the ADDIE model. The step consists of Analysis, Design, Development, and Evaluations. The results show that the developed media is valid and practical. The trial results to ten students show that the media is good. The other than Mobile learning can increase students learning, it can be seen by pretest and posttest results that show significant value. Mobile learning can help students understand the form and space in the material of solid geometry.

Keywords: Android, Solid Geometry, Learning Media, Mobile learning.
\end{abstract}




\section{Pendahuluan}

Matematika merupakan salah satu pelajaran yang penting dikuasai siswa di sekolah karena kegunaannya untuk memecahkan masalah kehidupan seharihari (Peluang, 2012; Sundayana, 2012; Afriansyah, 2013; Nurhaeni \& Basuki, 2013; Siregar, 2016; Mayasari \& Afriansyah, 2016; Sadiyono \& Sri, 2014; Setyaningrum \& Mampouw, 2020). Melalui pembelajaran matematika yang ada di sekolah siswa dilatih untuk berpikir sistematis, logis, kritis, serta mengembangkan sikap gigih dan percaya diri dalam menyelesaikan permasalahan yang ada (Prihandoko, 2006; Sadiyono, 2014; Pangestu \& Yunianta, 2019; Afriansyah, Herman, Turmudi, \& Dahlan, 2020).

Meskipun penting untuk dipelajari, masih banyak siswa yang merasa kesulitan untuk mempelajari matematika, salah satunya adalah geometri, khususnya materi Bangun Ruang Sisi Lengkung (Erleni, dkk., 2015; Yani, dkk., 2019). Banyak faktor yang menyebabkan kesulitan siswa dalam memahami materi tersebut diantaranya seperti: siswa tidak tertarik dengan Bangun Ruang Sisi Lengkung, siswa tidak mampu memberikan nama dari bagian tabung dan unsur-unsur bola, siswa tidak mampu mengingat rumus luas permukaan dan volume tabung, kerucut, dan bola, dan siswa tidak mampu menggunakan rumus luas permukaan dan volume tabung, kerucut, dan bola (Arifin dkk., 2017;
Sipayung, 2018; Hutajulu, Senjawati, \& Minarti, 2019; Nursyahidah, Saputro, Albab, \& Aisyah, 2020). Kenyataan yang menunjuk bahwa banyak siswa mengalami kesulitan dalam materi geometri juga dapat dilihat dari hasil survei Programme for Internasional Student Assessment (PISA) (2000) yang menunjukkan bahwa siswa lemah dalam materi tersebut, khususnya dalam pemahaman bentuk dan ruang. Padahal bentuk dan ruang mempunyai pengaruh positif terhadap kesuksesan siswa dalam memahami bentuk abstrak sebuah bangun ruang termasuk unsur dan sketsanya (Alias dkk., 2002; Afriansyah, 2015; Razak \& Kamaruddin, 2018; Mulyo, Sari, \& Syarifuddin, 2019; Nanang \& Sukandar, 2020).

Kesulitan-kesulitan yang dialami siswa dapat diatasi dengan menggunakan Mobile learning. Mobile learning merupakan suatu pembelajaran yang pembelajarnya (learner) tidak diam pada satu tempat atau kegiatan pembelajaran yang terjadi ketika pembelajar memanfaatkan perangkat teknologi bergerak (Malley, 2005). Mobile learning memungkinkan di manipulasi untuk mempermudah dalam proses pembelajaran, dan dapat menjadi suatu alternatif media belajar khususnya di bidang matematika (Atika, 2016; Lisnani \& Pranoto, 2020), mempermudah siswa dalam mempelajari materi.

Mobile learning memiliki berbagai manfaat bagi siswa, antara lain: 
meningkatkan keterlibatan, motivasi, dan antusias siswa untuk belajar, memperbaiki rasa ingin belajar mandiri, rasa memiliki terhadap belajar dan motivasi diri, memperbaiki ketepatan waktu dan kehadiran dalam belajar, meningkatkan partisipasi siswa dengan kesulitan belajar dan keterbatasan dalam belajar (Attewell, 2009). Clark Quinn dalam (Pratama dkk., 2018) menyatakan bahwa penggabungan antara mobile dan e-learning akan memperluas akses terhadap sumber daya, kemampuan pencairan yang kuat, memperkaya interaksi serta mendukung akses yang tidak akan terbatas ruang dan waktu.

Terdapat beberapa peneliti yang mengembangkan media mobile learning dalam materi Bangun Ruang Sisi Lengkung, diantaranya adalah Winarto (2018) dan Atika (2016). Winarto (2018) melakukan penelitian tentang Mobile learning pada materi irisan kerucut, sedangkan Atika (2016) mengembangkan aplikasi bulaker adventure game pada materi Bangun Ruang Sisi Lengkung. Hasil penelitian kedua peneliti tersebut menunjukkan bahwa mobile learning dapat membantu siswa mempelajari dan memahami materi matematika. Namun demikian, kedua peneliti masih memiliki kelemahan yaitu sebagai berikut: hanya dapat diinstal pada samartphone berbasis android, jumlah butir soal dalam latihan yang masih terbatas, tidak ada animasi membuka pada materi kerucut.
Melihat dari uraian peneliti terdahulu dan apa yang dibutuhkan oleh siswa untuk membantu mempelajari kembali materi yang kurang dikuasai dimanapun dan kapanpun. Peneliti berharap dengan dikembangkannya media pembelajaran mobile learning, siswa dapat mengatasi kesulitan dalam pemahaman materi. Tujuan penelitian ini adalah untuk mengembangkan mobile learning sebagai sarana belajar dan membantu siswa dalam memahami materi.

\section{Metode}

Jenis penelitian ini merupakan penelitian pengembangan atau Research and Development (R\&D) dengan model pengembangan ADDIE yang memiliki 5 tahapan, yaitu: analysis, design, development, implementation, evaluation. Penelitian ini dilakukan untuk menghasilkan produk (Abdullah, 2018; Khoirudin \& Rizkianto, 2018; Alam \& Razak, 2018; Puspandari, Praja, \& Muhtarulloh, 2019). Produk yang akan dihasilkan berupa media pembelajaran matematika berbasis android yang dikemas dalam bentuk mobile learning pada materi Bangun Ruang Sisi Lengkung untuk siswa SMP, media ini akan diujicobakan kepada 10 siswa kelas 9 SMP.

Teknik pengumpulan data yang digunakan berupa: lembar validasi media, lembar validasi kepraktisan, lembar validasi materi, lembar tes, dan lembar pendapat siswa. Rentang skor yang 
digunakan oleh peneliti berdasarkan skala Likert dengan model skala empat.

\section{Hasil dan Pembahasan}

\section{A. Hasil Penelitian}

1) Tahap Analisis (Analysis)

Pengembangan mobile learning Barusikung untuk siswa SMP dilakukan melalui 2 tahapan yaitu analisis kebutuhan dan analisis kinerja. Tahap analisis kebutuhan menunjukkan ada kebutuhan media pembelajaran yang dapat membantu siswa memahami materi dan berlatih mengerjakan soal latihan. Media pembelajaran yang dibutuhan tidak hanya membantu memahami materi namun mampu membantu siswa membangun semangat belajar, meningkatkan rasa ingin belajar secara mandiri.

\section{2) Tahap Desain (Design)}

Tahap berikutnya setelah analisis yaitu tahap desain. Pada tahap ini dilakukan dengan merancang tema dan latar belakang untuk mobile learning. Desain mobile learning memuat gambar yang menarik sehingga siswa akan tertarik untuk belajar. Merancang penyusunan materi agar mudah dipahami siswa secara ringkas dan menggunakan bahasa yang mudah dimengerti sehingga media ini dapat mempermudah siswa dalam belajar. Media pembelajaran diberi nama "BARUSIKUNG: Bangun Ruang Sisi Lengkung". Berikut adalah Prtotype mobile learning yang akan dikembangkan dapat dilihat pada Gambar 1.

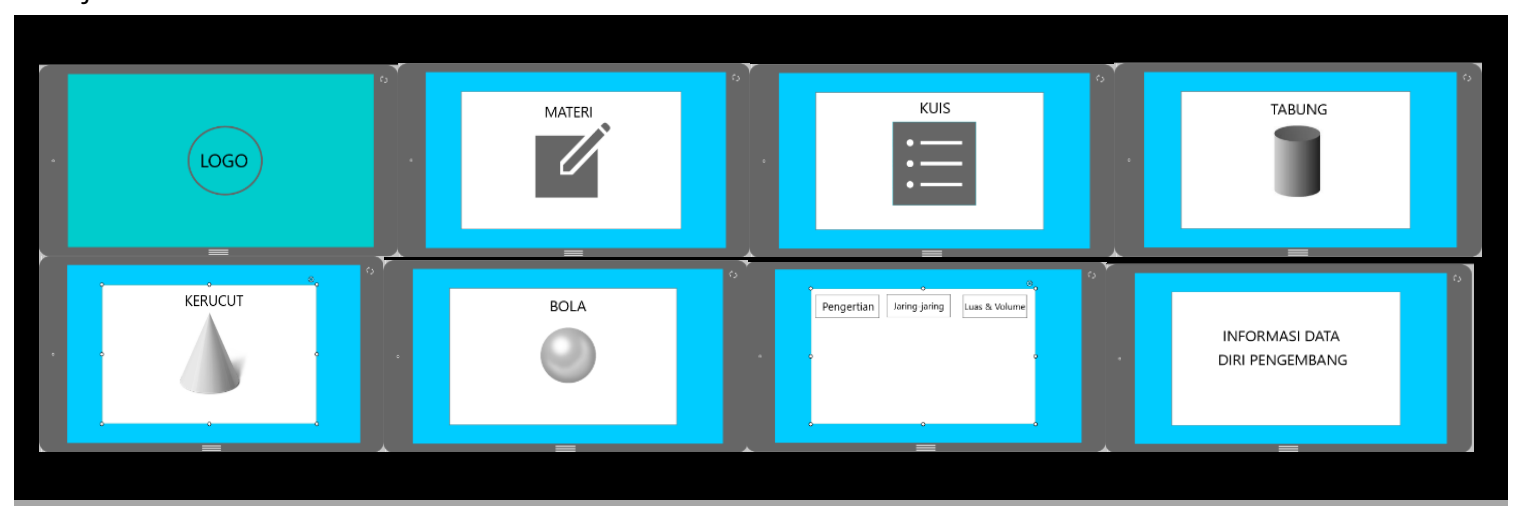

Gambar 1. Prototype Mobile Learning.

Prototype ini digunakan untuk Pembuat. Ada beberapa komponen lain mempermudah pengembang dalam yang mendukung media pembelajaran menentukan dan membuat rancangan. Rancangan mobile learning yang akan dibuat terdiri dari : 1) Halaman awal agar menarik dengan menggunakan animasi dibagian jaring-jaring, suara, dan gambar.

media; 2) Materi, di dalam materi terdiri dari bangun ruang tabung, kerucut, dan bola; 3) Kuis, yang berisi berbagai soal sebagai bahan latihan; 5) Informasi

3) Tahap Pengembangan (Development)

Setelah tahap desain mobile learning selesai berikutnya yaitu tahap 
pengembangan. Tahap ini untuk membuat mobile learning berdasarkan desain. Pengembangan mobile learning matematika ini dibuat menggunakan Unity dan CorelDraw. CorelDraw untuk membuat desain mobile learning sedangkan Unity untuk membuat aplikasi media. Berikut adalah deskripsi dari pengembangan media yang dilakukan.

a) Halaman Awal Media

Halaman awal media ini terdiri dari nama media dan bentuk logo. Nama media yang dikembangkan adalah "BARUSIKUNG" sedangkan logonya dengan menggunakan gambar-gambar Bangun Ruang Sisi Lengkung. Untuk

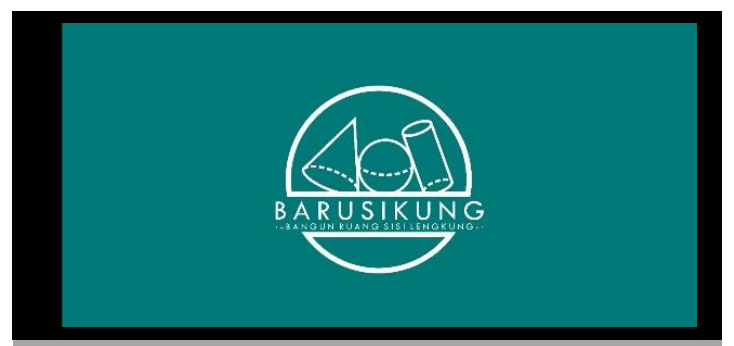

Gambar 2. Tampilan Awal.

\section{b) Menu Utama}

Pada menu utama terdapat pilihan materi dan kuis. Siswa dapat menggeser icon untuk memilih materi atau kuis yang akan dibuka terlebih dahulu. Selain materi dan kuis terdapat tombol informasi pembuat (1) dan tombol exit seperti pada Gambar 3. memulai siswa dapat memilih icon logo seperti yang terlhat pada Gambar 2.

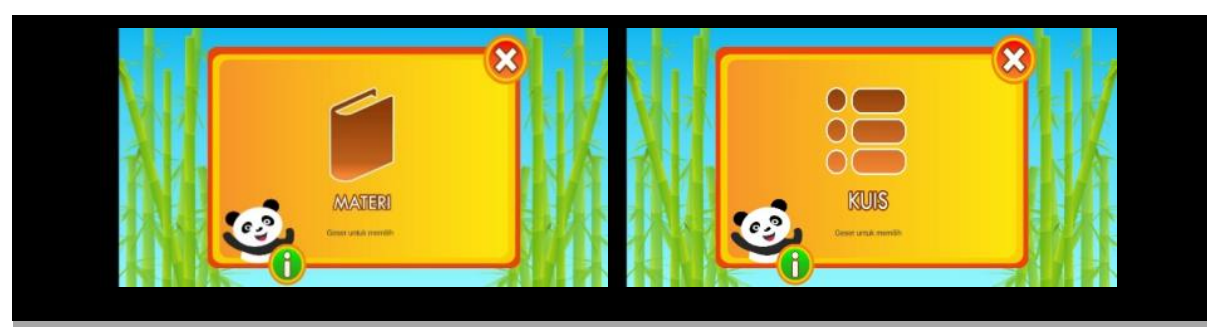

Gambar 3. Menu Utama.

c) Materi

Apabila tombol materi dipilih maka akan ditampilkan materi Bangun Ruang Sisi Lengkung yang terdiri dari materi tabung, kerucut, dan bola. Pada masing-masing sub materi tersebut akan dijelaskan tentang pengertian, jaring-jaring, luas dan volume masing-masing bangun ruang tersebut. Berikut adalah tampilan media ketika tombol materi di klik. 


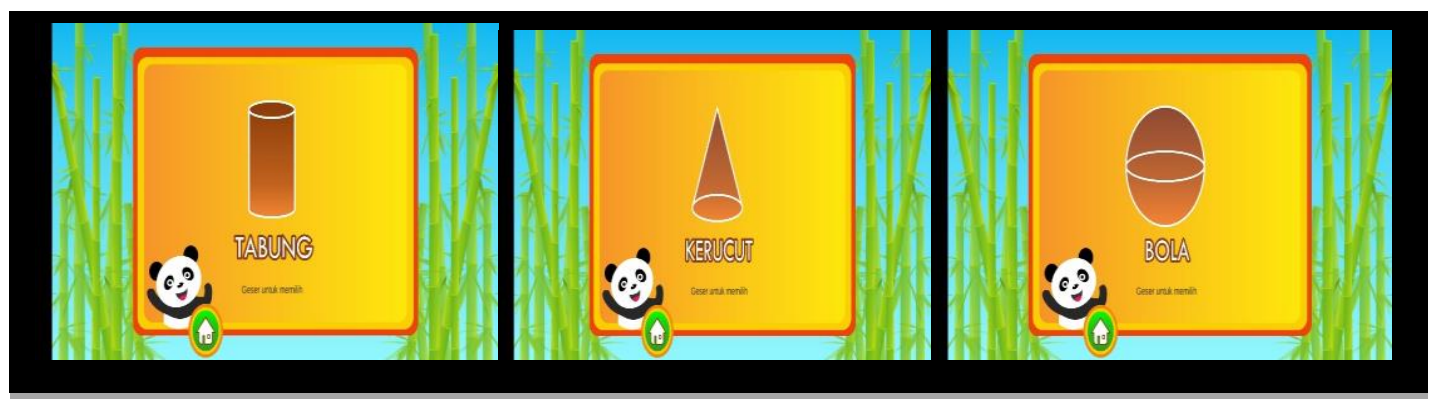

Gambar 4. Menu Materi.

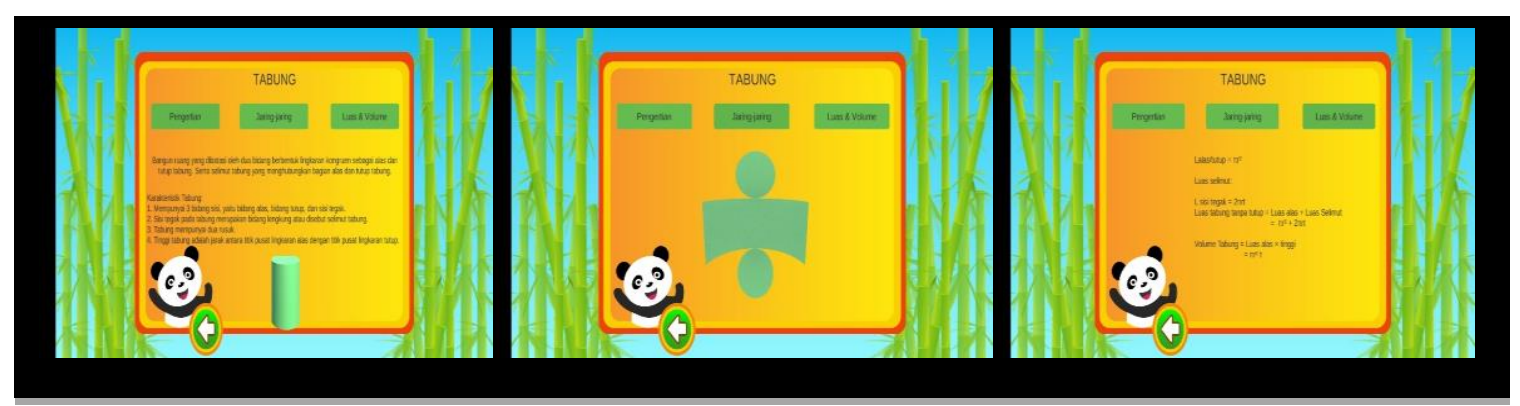

Gambar 5. Contoh Tampilan pada Materi Tabung.

d) Kuis

Kuis berisi soal-soal latihan yang terdiri dari 20 soal pilihan ganda. Terdapat soal-soal yang sesuai dengan setiap sub materi yang disajikan. Soal yang disediakan terdiri dari beberapa level baik mudah, sedang maupun sukar. Setelah soal-soal dikerjakan akan muncul pembahasan dari setiap soal yang dikerjakan. Terdapat skor pengerjaan pada tampilan soal, seperti pada Gambar 6.

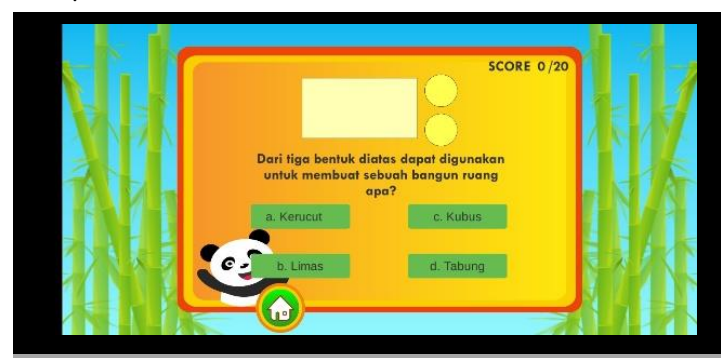

Gambar 6. Contoh tampilan latihan soal. e) Informasi Pembuat

Informasi pembuat berisi data diri tentang pembuat Mobile learning, tampilan informasi pembuat dapat dilihat pada Gambar 7.

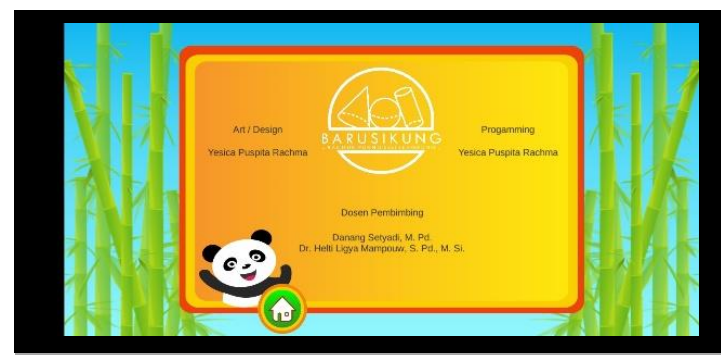

Gambar 7. Tampilan profil pembuat.

Setelah media pembelajaran dikembangkan kemudian dilakukan penilaian media untuk memperoleh kritik dan saran yang berguna sebagai acuan dalam perbaikan media. Hal tersebut dilakukan dengan menggunakan validasi media, validasi materi dan uji kepraktisan. Penilaian validasi media diperoleh skor 
rerata 3,0 yang artinya valid, hasil kepraktisan oleh ahli diperoleh skor rerata 3,0 yang artinya valid dan hasil penilaian materi diperoleh skor rerata 3,0 yang artinya valid. Media Mobile learning dinyatakan layak diuji coba di lapangan dengan revisi.
Setelah divalidasi media direvisi berdasarkan masukan validator-validator tersebut. Berikut adalah perbandingan media sebelum dan sesudah direvisi. Sehigga peneliti melakukan revisi tersebut. Media sebelum dan sesudah direvisi dapat dilihat pada Tabel 2.

Tabel 2. Perbedaan Media BARUSIKUNG.

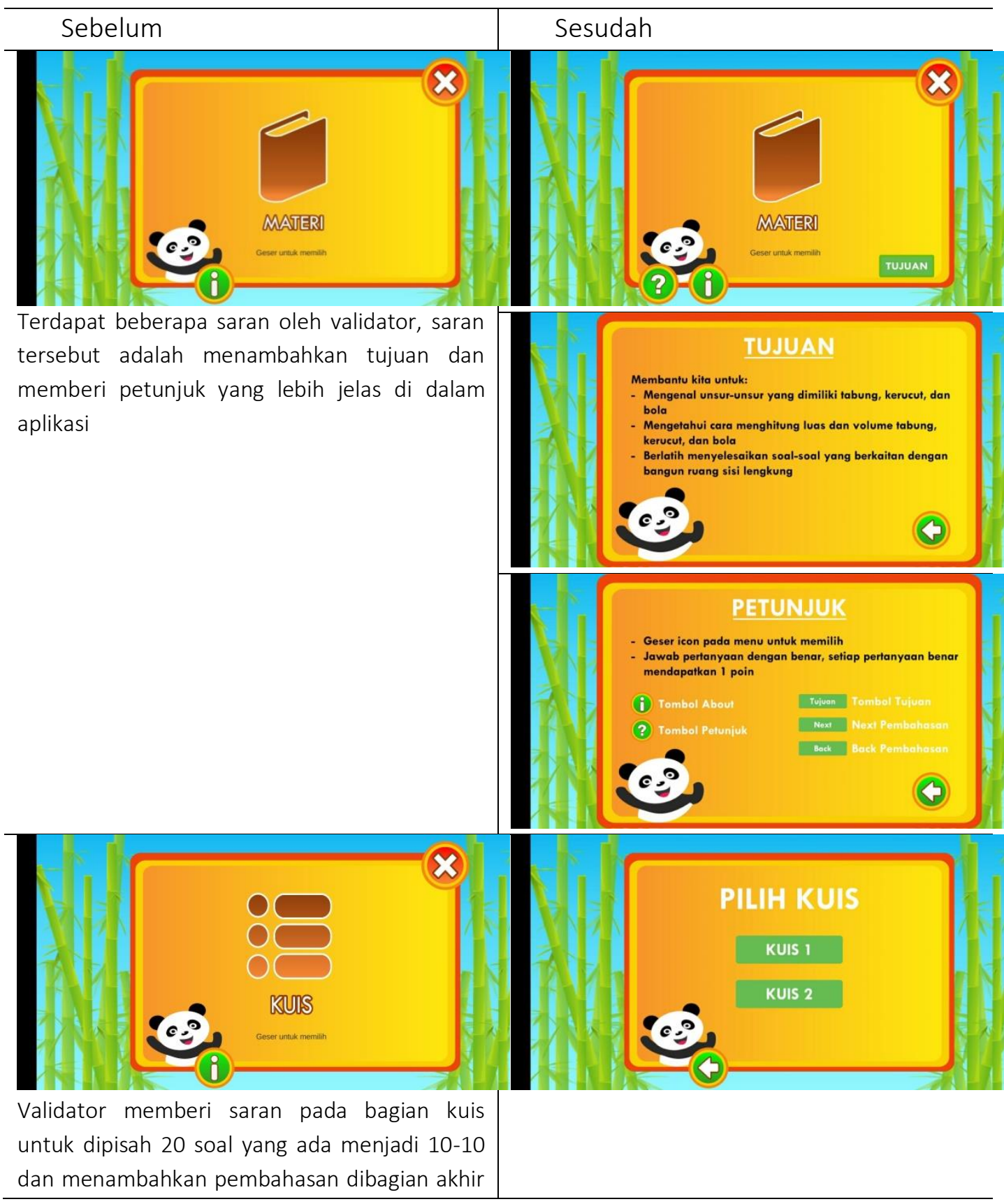


setelah menyelesaikan soal yang disediakan.

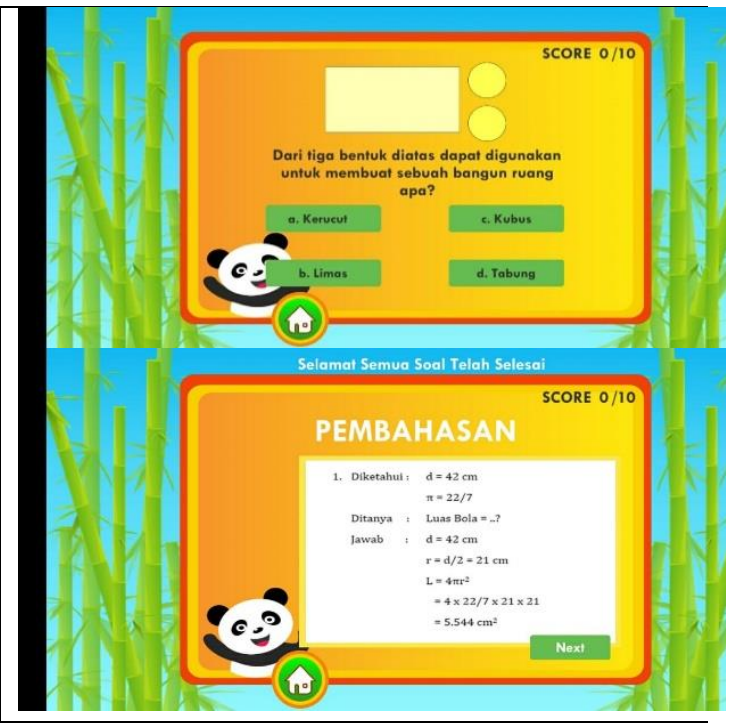

4) Tahap Implementasi (Implementation)

Tahap berikutnya setelah proses validasi adalah tahap implementasi. Media ini diuji cobakan kepada 10 siswa kelas 9 SMP. Pada saat uji coba berlangsung siswa diminta untuk mengisi angket respon siswa dengan cara menuliskan pendapatnya diangket yang sudah disediakan. Berikut adalah hasil dari respon tersebut pada Tabel 3.

Tabel 3. Respon siswa

\begin{tabular}{c|c|c|c|c|c|c}
\multicolumn{7}{c}{ Tabel 3. Respon siswa } \\
\hline \multirow{2}{*}{ Subjek } & \multicolumn{7}{c}{ Item } \\
\cline { 2 - 7 } & I & 2 & 3 & 4 & 5 & 6 \\
\hline 1 & S & S & S & S & S & S \\
\hline 2 & SS & S & SS & S & S & S \\
\hline 3 & S & S & SS & SS & S & S \\
\hline 4 & SS & S & S & S & S & S \\
\hline 5 & SS & S & SS & S & SS & SS \\
\hline 6 & S & SS & S & S & S & S \\
\hline 7 & SS & SS & S & S & SS & S \\
\hline 8 & S & SS & SS & S & S & S \\
\hline 9 & SS & SS & S & S & S & SS \\
\hline 10 & SS & SS & S & SS & SS & S \\
\hline
\end{tabular}

\section{5) Tahap Evaluasi (Evaluations)}

Pada tahap evaluasi bertujuan untuk melihat sejauh mana mobile learning matematika

berperan

dalam

meningkatkan pemahaman siswa, sebelum menggunakan media yang dikembangkan hal ini dilakukan dengan cara memberikan pretest dan post test. Berikut Tabel 4 adalah data hasil belajar siswa sebelum dan sesudah menggunakan mobile learning.

Tabel 4.

Skor dari Pretest dan Pretest

\begin{tabular}{|c|c|c|c|c|c|c|c|c|}
\hline \multicolumn{9}{|c|}{ Paired Samples Test } \\
\hline & \multicolumn{5}{|c|}{ Paired Differences } & \multirow{3}{*}{$\mathrm{T}$} & \multirow{3}{*}{\multicolumn{2}{|c|}{ Sig. }} \\
\hline & \multirow[t]{2}{*}{ Mean } & \multirow[t]{2}{*}{$\begin{array}{c}\text { Std. } \\
\text { Deviation }\end{array}$} & \multirow[t]{2}{*}{$\begin{array}{c}\text { Std. Error } \\
\text { Mean }\end{array}$} & \multicolumn{2}{|c|}{$\begin{array}{l}95 \% \text { Confidence interval } \\
\text { of the Difference }\end{array}$} & & & \\
\hline & & & & Lower & Upper & & & \\
\hline $\begin{array}{l}\text { Tair } 1 \text { Pre Test- } \\
\text { Post Test }\end{array}$ & 7,30000 & 2.54078 & .80346 & 9.11756 & 5.48244 & & & \\
\hline
\end{tabular}

Jika nilai Sig. (2-tailed) < 0,05, maka terdapat perbedaan yang signifikan antara hasil belajar pada data pretest dan posttest. Berdasarkan Tabel 4, dapat dilihat bahwa nilai signifikan dari pretest dan posttest adalah 0,000 $(0,000<0,05)$ yang artinya ada perbedaan dari hasil belajar setelah dan sebelum menggunakan media. 


\section{B. Pembahasan}

Berdasarkan hasil penelitian tersebut dapat diketahui bahwa media yang dikembangkan valid dan praktis. Hasil uji coba terhadap siswa menunjukkan bahwa media mampu meningkatkan pemahaman siswa. Hal ini sejalan dengan pendapat (Pratama dkk, 2018) bahwa mobile learning dapat dimanfaatkan siswa untuk menyelesaikan masalah belajar dan memudahkan dalam mempelajari suatu materi. Sebagai salah satu fasilitas siswa dalam memperoleh informasi elektronik untuk mencapai pengetahuan tanpa mempermasalahkan waktu dan lokasi (Maulana, 2017), dengan adanya mobile leaening siswa dapat mempelajari kapan saja dan di mana saja.

Kelebihan dari media yang dikembangkan adalah memiliki tampilan yang menarik, dapat digunakan dimana dan kapan saja tanpa terhubung dengan internet, Mobile learning dapat diinstal di semua smartphone, memiliki animasi bangun ruang yang dapat membuka dan menutup sendiri. Namun demikian, masih terdapat kekurangan seperti rumus atau tulisan yang penting tidak dperjelas, media belum dapat didownload di playstore.

\section{Penutup}

Peneliti mengembangkan aplikasi media pembelajaran berbasis android dengan harapan dapat membantu siswa dalam memahami materi Bangun Ruang Sisi Lengkung dan membuat aplikasi menjadi menarik agar siswa tidak bosan untuk mempelajarinya. Siswa dapat menggunakan secara mandiri sehingga lebih efektif dalam belajar.

Media pembelajaran matematika BARUSIKUNG dapat membantu siswa dalam belajar dan membangkitkan semangat belajar mereka karena tampilan yang menarik dapat memotivasi.

\section{DAfTAR PUStaka}

Abdullah, S. F. (2018). Pengembangan Media Pembelajaran Matematika Trigo Fun Berbasis Game Edukasi Menggunakan Adobe Animate pada Materi Trigonometri. Jurnal Pendidikan Matematika FKIP Univ. Muhammadiyah Merto.

Afriansyah, E. A. (2013). Design Research: Mengukur Kepadatan Bilangan Desimal. In Seminar Nasional Matematika dan Pendidikan Matematika STKIP Siliwangi (Vol. 1).

Afriansyah, E. A. (2015). Students' Misconception in Decimal Numbers. In International Seminar on Teacher Education 1st ISTE UIN Suska Riau.

Afriansyah, E. A., Herman, T., Turmudi, T., \& Dahlan, J. A. (2020). Mendesain Soal Berbasis Masalah untuk Kemampuan Berpikir Kritis Matematis Calon Guru. Mosharafa: Jurnal Pendidikan Matematika,9(2), 239250.

Alam, Z. I., \& Razak, F. (2018). Pengembangan Lembar Kegiatan Siswa Berbasis Metode Penemuan Terbimbing untuk Pembelajaran 
Matematika pada Siswa Kelas XII SMA Negeri 1 Segeri. Mosharafa: Jurnal Pendidikan Matematika, 7(1), 1-12.

Alias, M., Black, T. R., \& Gray, D. E. (2002). Effect of instructions on spatial visualisation ability in civil engineering students. International Education Journal, 3(1), 1-12.

Amirullah, G., \& Hardinata, R. (2017). Pengembangan Mobile learning Bagi Pembelajaran. JKKP (Jurnal Kesejahteraan Keluarga Dan Pendidikan), 4(02), 97-101.

Arifin, Yusmin, E., \& Hamdani. (2017). Analisis Kesulitan Belajar Siswa pada Materi Bangun Sisi Lengkung di SMP. Jurnal Pendidikan Dan Pembelajaran (JPP), 6(4), 1-13.

Attewell, J. (2009). The Impact Of Mobile learning. $L S N$

Buchori, Rasiman, Prasetyowati \& Kartinah. (2015). Desain Produk Mobile learning Pada Mata Kuliah Geometri Dengan Pendekatan Matematik Realistik. Seminar Nasional Teknologi Pendidikan UM.

Erleni, F. A. F. (2015). Rancang Bangun Alat Bantu Ajar Matematika pada Materi Bangun Ruang Berbasis Multimedia (Study Kasus SMP Negeri 01 Bangkinang Seberang). ASTIN - Sains dan Teknolofi Informasi, 1.

Gunawan, I. (2011). Pengembangan Aplikasi Mobile learning Fisika Sebagai Media Pembelajaran Pendukung. Jurnal Ilmiah Pendidikan Fisika Al-BiRuNi.
Hutajulu, M., Senjayawati, E., \& Minarti, E. D. (2019). Analisis Kesalahan Siswa SMK Dalam Menyelesaikan Soal Kecakapan Matematis Pada Materi Bangun Ruang. Mosharafa: Jurnal Pendidikan Matematika,8(3), 365376.

Khoirudin, K., \& Rizkianto, I. (2018). Pengembangan Perangkat Pembelajaran Problem Based Learning dan Learning Trajectory yang Berorientasi pada Kemampuan Penalaran Matematis Siswa. Mosharafa: Jurnal Pendidikan Matematika, 7(2), 207-218.

Pranoto, Y. H. (2020). Peningkatan Pemahaman Konsep Bilangan Bulat Melalui Cerita Si Unyil Berbasis ICT. Mosharafa: Jurnal Pendidikan Matematika, 9(2), 215-226.

Malley, C. O., Vavoula, G. Ruang, Glew, J. P., Taylor, J., Sharples, M., Lonsdale, P., Naismith, L., Waycott, J., Malley, C. O., Vavoula, G., Glew, J. P., Taylor, J., \& Sharples, M. (2005). Guidelines for learning / teaching / tutoring in a mobile environment To cite this version: Public Deliverable from the MOBILearn Project (D.4.1).

Maulana, L. (2017). Pengembangan Media Pembelajaran Berbasis Mobile learning Platform Android Keselamatan Kesehatan Kerja Dan Lingkungan Hidup ( K3Lh ) Pada Program Studi Ketenagalistrikan Untuk Materials for Students of Electrical Power Study Program of. 
Program Studi Pendidikan Teknik Mekatronika, 7(2), 197-207.

Mayasari, Y., \& Afriansyah, E. A. (2016).

Kemampuan Koneksi Matematis

Siswa Melalui Model Pembelajaran

Berbasis Masalah (Studi Penelitian di SMP Negeri 5 Garut). Jurnal Riset Pendidikan, 2(01), 27-44.

Mulyo, M. R. G. T., Sari, A. F., \& Syarifuddin, A. (2019). Proses Berpikir Siswa Bergaya Kognitif Visualizer dalam Menyelesaikan Masalah TIMSS Non Geometri. Mosharafa: Jurnal Pendidikan Matematika,8(1), 167178.

Nanang, N., \& Sukandar, A. (2020). Meningkatkan Kemampuan Siswa SDIT Miftahul Ulum Pada Operasi Bilangan Bulat Melalui CAIContextual. Mosharafa: Jurnal Pendidikan Matematika, 9(1), 71-82.

Nurhaeni, K., \& Basuki, B. (2013).

Perbedaan Kemampuan Pemecahan Masalah Matematik Siswa antara yang Menggunakan Metode Student Teams Achievement Division dengan Teams Games Tournament. Mosharafa: Jurnal Pendidikan Matematika, 2(1), 23-36. Nursyahidah, F., Saputro, B. A., Albab, I. U., \& Aisyah, F. (2020). Pengembangan Learning Trajectory Based Instruction Materi Kerucut Menggunakan Konteks Megono Gunungan. Mosharafa: Jurnal Pendidikan Matematika, 9(1), 47-58.
(2019). Proses Berpikir Kreatif Matematis Siswa Extrovert dan Introvert SMP Kelas VIII Berdasarkan Tahapan Wallas. Mosharafa: Jurnal Pendidikan Matematika,8(2), 215226.

Peluang, J. (2012). Pendekatan Realistik dalam Pembelajaran Matematika. Jurnal Peluang, 1(1), 81.

Pratama, R. A., Ulfa, S., \& Kuswandi, D. (2018). Mobile learning Berbasis Game Based Learning Pelajaran Matematika Pokok Bahasan Bangun Ruang Sisi Datar. Jurnal Pendidikan: Teori, Penelitian, Dan Pengembangan, 3(6), 771-777.

Puspandari, I., Praja, E. S., \& Muhtarulloh, F. (2019). Pengembangan Bahan Ajar dengan Pendekatan Induktif untuk Meningkatkan Kemampuan Representasi Matematis Siswa SMP. Mosharafa: Jurnal Pendidikan Matematika, 8(2), 307-318.

Putri, Atika Khaulah. (2016). Pengembangan Aplikasi Bulaker Adventure Game Sebagai Media Belajar Berbasis Android Pada Materi Bangun Ruang Sisi Lengkung. Jurnal Ilmiah Pendidikan Matematika, 3(5).

Razak, F., \& Kamaruddin, R. (2018). Pengaruh Sikap Ilmiah Siswa terhadap Hasil Belajar Materi Bangun Ruang Siswa Kelas VIII SMP Negeri 3 Minasatene. Mosharafa: Jurnal Pendidikan Matematika,7(1), 133142.

Sadiyono, B. (2014). Model Pembelajaran 
Reciprocal Teaching Pada Pelajaran Matematika untuk Meningkatkan Berfikir Kritis dan Prestasi Belajar. Mosharafa: Jurnal Pendidikan Matematika, 3(1), 25-30.

Sadiyono, B., \& Sri, S. (2014). Pendekatan Contextual Teaching And Learning untuk Meningkatkan Prestasi Belajar pada Bidang Matematika. Mosharafa: Jurnal Pendidikan Matematika, 3(2), 67-74.

Setyaningrum, D. U., \& Mampouw, H. L. (2020). Proses Metakognisi Siswa SMP dalam Pemecahan Masalah Perbandingan Senilai dan Berbalik Nilai. Mosharafa: Jurnal Pendidikan Matematika, 9(2), 275-286.

Sipayung, A. (2018). Meningkatkan Pemahaman Konsep Matematika tentang Sifat-Sifat Bangun Ruang Sederhana melalui Contextual Teaching and Learning. Mosharafa: Jurnal Pendidikan Matematika, 7(3), 401-412.

Siregar, I. (2016). Masalah Pembelajaran Pembuktian Matematika bagi Mahasiswa di Indonesia. Mosharafa: Jurnal Pendidikan Matematika, 5(3), 315-324.

Sugiyono. (2016). Metode Penelitian \& Pengembangan Research And Development. Bandung: Alfabeta .

Sundayana, R. (2012). Faktor-Faktor Yang Mempengaruhi Kemampuan Mahasiswa Dalam Praktikum Analisis Data Statistik. Mosharafa: Jurnal Pendidikan Matematika, 1(1), 35-42.
Winarto, A. C. W. E., \& Yunianta, T. N. H. (2018). Pengembangan Mobile learning Matematika Sebagai Suplemen Belajar SMA Kelas XI Pada Materi Irisan Kerucut. HISTOGRAM: Jurnal Pendidikan Matematika, 2(1), 32.

Yani, C. F., Maimunah, M., Roza, Y., Murni, A., \& Daim, Z. (2019). Analisis Kemampuan Pemahaman Matematis Siswa pada Materi Bangun Ruang Sisi Lengkung. Mosharafa: Jurnal Pendidikan Matematika,8(2), 203214.

\section{Riwayat Hidup PENUlis}

Yesica Puspita Rahman, S.Pd.

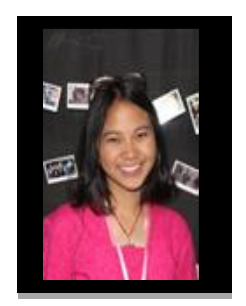

Lahir di Kabupaten Pati, 08 September 1998. Mahasiswi Program Studi S1 Prodi Pendidikan Matematika FKIP Universitasa Kristen Satya Wacana

\section{Danang Setyadi, S.Pd., M.Pd.}

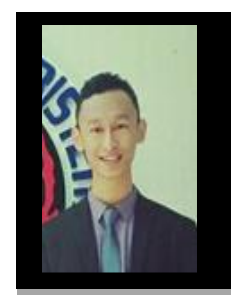

Staf pengajar di Progdi Pendidikan Matematika Universitas Kristen Satya Wacana, Salatiga

\section{Dr. Helti Lygia Mampouw, S.Pd., M.Si.}

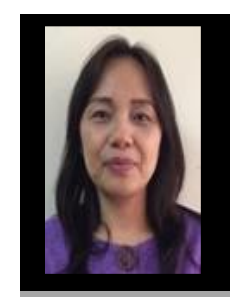

Staf pengajar di Progdi Pendidikan Matematika Universitas Kristen Satya Wacana, Salatiga. 